\title{
Potent antibacterial activity of Dihydydropyrimidine- 1,3,5-triazines via inhibition of DNA gyrase and antifungal activity with favourable metabolic profile
}

\section{Anup Masih}

Sam Higginbottom University of Agriculture Technology and Sciences

Jitendra Kumar Shrivastava

Sam Higginbottom University of Agriculture Technology and Sciences

Hans Raj Bhat

Dibrugarh University

Udaya Pratap Singh ( $\nabla$ udaysingh98@gmail.com )

Allahabad Agricultural Institute-Deemed-to-be-University https://orcid.org/0000-0003-0865-0502

Research article

Keywords: 1,3,5-triazine, antibacterial, antibiofilm, DNA gyrase inhibition, metabolic prediction

Posted Date: October 15th, 2019

DOI: https://doi.org/10.21203/rs.2.15956/v1

License: (a) (i) This work is licensed under a Creative Commons Attribution 4.0 International License.

Read Full License 


\section{Abstract}

The compounds were tested against panel of three Gram-positive, viz. Staphylococcus aureus, Bacillus subtilis, Bacillus cereus and three Gram-negative bacterial strains viz. Pseudomonas aeruginosa, Escherichia coli, and Proteus vulgaris for determination of their antibacterial efficacy using cefixime as a standard drug. The antibiofilm activities of the compounds were determined against Staphylococcus aureus, and Bacillus subtilis. The most potent compounds $7 \mathrm{I}$ amd $7 \mathrm{~m}$ found bacteriostatic in time kill assay via inhibition of DNA Gyrase enzyme. The metabolic liability of compound $7 \mathrm{~m}$ was determined using RS-Predictor and MetaPrint 2D React. The antifungal activity against human fungal pathogens was also estimated, where these compounds showed considerable activity in comparison to standard. The in vivo antibacterial activity of compound $7 \mathrm{~m}$ was also determined using $\mathrm{S}$. aureus induced murine infection model.

\section{Background}

The past few decades have witnessed the discovery of new antibiotics and derivatives thereof which has enhances our capacity to fight against the infectious diseases [1,2]. This has made enormous impact on the on the lives of whole mankind across the globe, and soon antibiotics was considered as a magic bullets of the $21^{\text {st }}$ century [3]. Unfortunately, the magical power of these bullets was proven wrong due to the emergence and worldwide spread of many new resistant pathogens which renders them ineffective [4]. This has seriously jeopardized the clinical utility of numerous antibiotics, threatening our ability to treat common infectious diseases [5]. The severity of the situation could be easily understood by the fact that, infectious diseases are now accounted for second leading cause of death worldwide [6]. In Unites States, as per the estimates, each year at least two million people are infected with resistant pathogens, of which 23,000 will die as a result of these infections [7]. The extensive misuse of antibiotics in humans and livestock together with few antibiotics in the clinical pipeline has aggravated the situation. This has led World Health Organisation (WHO) to warn the emergence of post-antibiotic era, in which common infections and minor injuries can once again kill [8].

Apart from the prudent use of antibiotics, newer strategies are being explored to curb the menace of resistance which include, repurposing old antibiotics into more potent and effective drug (eg. modification of spectinomycin), combination of two or more antibiotic agents, supplementation with adjuvants and search of novel antibiotics [9-11]. The later approach is found advantageous in many ways such as; newer agents are endowed with better efficacy, better pharmacokinetics and enhanced chemical stability [12]. In addition to the above, more importantly, these agents are less prone to mutation which makes them clinically relevant for the longer period of time [13].

In recent years, our group have exploited various pharmacological properties of 1,3,5-triazines, which includes antimalarial [14], antidiabetic [15], anticancer and against cystic fibrosis [16]. More specifically, we have developed various novel series of substituted 1,3,5-triazines as potent and novel class of antibacterial agents $[17,15]$. Based on the structure-activity relationship studies, we have optimized hybrid 
thiazolidine-1,3,5-triazine derivatives as potent antibacterial and antibiofilm agents [18]. In our recent study, we have developed various dihydydropyrimidine-1,3,5-triazines as potent anti-breast cancer agent [19], thus concerning the importance of dihydydropyrimidine and 1,3,5-triazine, we wish to determine the effect of these derivatives against bacterial infections and investigation of mechanism underlying the inhibitory effect.

\section{Materials And Methods}

\section{Compounds}

The synthesis of compounds was achieved as described previously and purity was confirmed by melting point, ${ }^{1} \mathrm{H}$ and ${ }^{13} \mathrm{C}$ NMR spectroscopy [19].

\section{Antibacterial Activity}

All synthesized compounds were screened for their minimum inhibitory concentration ( $\mathrm{MIC}, \mu \mathrm{g} / \mathrm{mL}$ ) against selected four Gram-positive, viz. Staphylococcus aureus (NCIM-2079), Bacillus subtilis (NCIM2063), Bacillus cereus (NCIM-2156), Staphylococcus Epidermidis and four Gram-negative bacterial strains viz. Pseudomonas aeruginosa (NCIM-2036), Escherichia coli (NCIM-2065), Proteus Mirabilis and Proteus vulgaris by the broth dilution method as recommended by the National Committee for Clinical Laboratory Standards with minor modifications [20]. Cefixime was used as standard antibacterial agent. Solutions of the test compounds and reference drug were prepared in dimethyl sulfoxide (DMSO) at concentrations of $100,50,25,12.5,6.25,3.125$ and $1.56 \mu \mathrm{g} / \mathrm{mL}$. Nine tubes were prepared in duplicate with the second set being used as MIC reference controls (16-24 h visual). After sample preparation, the controls were placed in a $37^{\circ} \mathrm{C}$ incubator and read for macroscopic growth (clear or turbid) the next day. Into each tube, $0.8 \mathrm{~mL}$ of nutrient broth was pipetted (tubes 2-8); tube 1 (negative control) received 1.0 $\mathrm{mL}$ of nutrient broth and tube 9 (positive control) received $0.9 \mathrm{~mL}$ of nutrient. Tube 1, the negative control, did not contain bacteria or antibiotic. The positive control, tube 9 , received $0.9 \mathrm{~mL}$ of nutrient broth because it contained bacteria but not antibiotic. The test compounds were dissolved in DMSO (100 $\mu \mathrm{g} / \mathrm{mL}) ; 0.1 \mathrm{~mL}$ of increasing concentration of the prepared test compounds is serially diluted from tube 2 to tube 7 from highest $\left(100 \mu \mathrm{g} \mathrm{mL}^{-1}\right)$ to lowest $\left(1.56 \mu \mathrm{g} \mathrm{mL}^{-1}\right)$ concentration (tubes 2-8 containing $100,50,25,12.5,6.25,3.125$ and $1.56 \mu \mathrm{g} \mathrm{mL}^{-1}$ ). After this process, each tube was inoculated with $0.1 \mathrm{~mL}$ of the bacterial suspension whose concentration corresponded to $0.5 \mathrm{McF}$ arland scale $\left(9 \times 10^{8} \mathrm{cells} / \mathrm{mL}\right)$, and each bacterium was incubated at $37^{\circ} \mathrm{C}$ for $24 \mathrm{~h}$ at $150 \mathrm{rpm}$. The final volume in each tube was 1.0 $\mathrm{mL}$. The incubation chamber was kept humid. At the end of the incubation period, MIC values were recorded as the lowest concentration of the substance that gave no visible turbidity, that is, no growth of inoculated bacteria.

\section{Antibiofilm Activity}




\section{Time Kill Assay}

The $S$. aureus in logarithmic growth phase were diluted to $\sim 10^{6} \mathrm{CFU} / \mathrm{mL}$ and exposed to concentrations equivalent to $1 / 2 \times \mathrm{MIC}, 1 \times \mathrm{MIC}, 2 \times \mathrm{MIC}, 4 \times \mathrm{MIC}$ and $8 \times \mathrm{MIC}$ (in triplicate) of compound $7 /$ and $7 \mathrm{~m}$ in tryptic soy broth. Aliquots $(100 \mu \mathrm{L})$ were collected from each treatment after $0,2,4,6$ and $24 \mathrm{~h}$ of incubation at $37^{\circ} \mathrm{C}$ and subsequently serially diluted in PBS. The bacteria were then transferred to tryptic soy agar plates and incubated

at $37^{\circ} \mathrm{C}$ for $18-20 \mathrm{~h}$ before viable $\mathrm{CFU} / \mathrm{mL}$ was determined [21].

\section{DNA Gyrase Inhibition Study}

The DNA gyrase A (S. aureus) assay of compound $7 m$ was carried out as previously reported [22]. Briefly, the $S$. aureus was cultured in medium B (2 g yeast extract, $10 \mathrm{~g}$ polypeptone, $1.2 \mathrm{~g}\left(\mathrm{NH}_{4}\right)_{2} \mathrm{SO}_{4}, 8 \mathrm{~g}$ $\mathrm{Na}_{2} \mathrm{HPO}, 2 \mathrm{~g} \mathrm{KH}_{2} \mathrm{PO}_{4}, 0.2 \mathrm{~g} \mathrm{MgSO}_{4}, 4 \mathrm{~g}$ glucose in $1 \mathrm{~L}$ distilled water). DNA gyrase purification, Supercoiling, and decatenation were executed as reported by F. Blanche [23]. The $I_{50}(\mu \mathrm{g} / \mathrm{mL})$ was determined from the dose response curve.

\section{In vivo anti-bacterial activity}

The antibacterial activity of compound $7 \mathrm{~m}$ was performed using female albino Wistar rats of $40-45$ days old, 180-200g b.w distributed in 5 groups ( $n=6 /$ each) [24]. Briefly, $S$. aureus was grown in the MüellerHinton broth $(\mathrm{MH})$ after reaching the log phase of growth; the suspension was centrifuged at $1000 \mathrm{xg}$ for $15 \mathrm{~min}$. The supernatant was discarded, and the bacterial pellet was re-suspended in phosphate buffer saline (PBS) to achieve a concentration of $4 \times 10^{6} \mathrm{CFU} / \mathrm{mL}$. All rats were inoculated intravenously (iv.) with $0.2 \mathrm{~mL}$ of $S$. aureus. After $1 \mathrm{~h}$ of inoculation, rats were treated with the vehicle (sterile PBS), Compound (three gradient dose) (p.o). A sham group was injected with sterile PBS in place of the bacterial suspension. Positive control group rats were treated with $60 \mathrm{mg} / \mathrm{kg}$ of amoxicillin (p.o). To perform the quantitative evaluation of the bacteria in the blood of all groups, the blood samples were taken by retroorbital puncture of rats after $1 \mathrm{~h}$ of treatment and the blood samples plated on blood agar plates. The plates were incubated at $37^{\circ} \mathrm{C}$ in ambient air overnight. The colonies of $S$. aureus were counted by colony counter. All experiments were done aseptically, while samples and contaminated materials were sterilized before being disposed.

\section{Metabolic Liability Prediction}

\section{RS Predictor}


The cytochrome P450-mediated sites of metabolism were determined using the web server of RS Predictor by uploading the SDF file format of the compound $7 m$ [25].

\section{MetaPrint2D-React}

The web platform (http://www-metaprint2d.ch.cam.ac.uk/) by uploading the SMILES string of compound $7 \mathrm{~m}$ was used to determine the SOM. The fingerprint matching was set to Loose, with the following values of parameters: number of exact levels: 2 ; similarity threshold: 1.0; first weight: 1.0; second weight: 1.0; third weight: 1.0 ; fourth weight: 0.75 ; fifth weight: 0.5 ; and sixth weight: 0.25 .

\section{Antifungal activity}

The synthesized compounds, clubbed thiazole-1,3,5-triazine derivatives were screened for their antifungal activity minimum inhibitory concentration (MIC) against $C$. albicans NCIM-3102, C. glabrata NCIM-3266, C. neoformans NCIM-3542, and A. niger NCIM-620 using modified broth microdilution method recommended by CLSI, using fungicidal amphotericin B as standard controls [26] The Candida spp. and $C$. neoformans strains were subcultured on Sabouraud dextrose agar at $35 \pm 1^{\circ} \mathrm{C}$ for $24 \mathrm{~h}$ and $48 \mathrm{~h}$ respectively, while $A$. niger strains were subcultured $35 \pm 1{ }^{\circ} \mathrm{C}$ for 4 days. The Candida spp. and C. neoformans suspensions were diluted with modified broth, RPMI 1640 medium at pH 4.5 in comparison to $0.5 \mathrm{McF}$ arland standard to afford final target inocula of $5.0 \times 10^{3}$ and $5.0 \times 10^{5}$ for Candida spp. and $C$. neoformans respectively and $A$. niger inoculum was made to $4.0 \times 10^{4}$ colony forming units (CFU)/mL at pH 7.3 with the same RPMI 1640 medium in 5\% Alamar blue. The fungal inocula were added to the samples to achieve a final volume of $200 \mu \mathrm{L}$. Eight serial dilutions, starting with $20.0000 \mu \mathrm{g} / \mathrm{mL}$ of the compounds (dissolved in dimethyl sulfoxide, DMSO) were made using $20 \%$ DMSO in normal saline to afford least concentration of $0.1563 \mu \mathrm{g} / \mathrm{mL}(=0.16 \mu \mathrm{g} / \mathrm{mL})$ and transferred in duplicate to 96-well flat-bottom microplates. All organisms were examined at $630 \mathrm{~nm}$ prior to and after incubation (Candida spp. at $37 \pm 1{ }^{\circ} \mathrm{C}, 18$ to $24 \mathrm{~h}$; while for $C$. neoformans and A. niger at $35 \pm 1{ }^{\circ} \mathrm{C}, 72 \mathrm{~h}$ ). The lowest test concentration that allowed no detectable growth (or no more than $20 \%$ growth for fluconazole, for $A$. niger, no color change from blue to pink) was defined as the minimum inhibitory concentration (MIC).

\section{Statistical analysis and ethical approval}

The results were expressed in terms of mean \pm standard deviation (SD). One-way analysis of variance (ANOVA) was used, followed by the Student-Newman-Keuls test when statistical difference was detected among the groups. Values of $p>0.05$ were considered significant. The GraphPad Prism@version5.01 for Windows (GraphPad Software, USA) was used for statistical analysis. The animal experiment was performed as per the Guide for the Care and Use of Laboratory Animals of and was permitted by the Institutional Animal Ethics Committee of SHUATS, Allahabad. 


\section{Results And Discussions}

\section{Antibacterial activity}

All synthesized compounds were screened for their minimum inhibitory concentration ( $\mathrm{MIC}, \mu \mathrm{gL}^{-1}$ ) against a panel of three Gram-positive, viz. Staphylococcus aureus (NCIM-2079), Bacillus subtilis (NCIM-2063), Bacillus cereus (NCIM-2156) and three Gram-negative bacterial strains viz. Pseudomonas aeruginosa (NCIM-2036), Escherichia coli (NCIM-2065), and Proteus vulgaris for determination of their antibacterial efficacy using cefixime as a standard drug and results were presented in Table 1. It was depicted from the results that entire set of molecules showed mild to moderate activity and even in some cases showed potent activity against tested microorganism. It is noteworthy to mention that the presence of substituent have marked effect on the activity profile as seen in the case of compound $7 b$ which showed excellent activity than its non-substituted counterpart, compound 7a. Further, isomeric replacements of substituent have not significantly altered the activity profile except in the case $E$. coli where compound $7 c$ exhibit equipotent activity to the reference drug. In the case of compounds $7(d-g)$ having electron withdrawing group on the $\mathrm{R}$ along with $-\mathrm{OH}$ and $-\mathrm{OCH}_{3}$ with different positions showed pronounced inhibition of Gram negative microorganism in comparison to Gram positive microorganism. To our surprise, drastic upsurge in activity against Gram positive microorganisms was reported by compound $7(h-m)$ having electron withdrawing groups on both the positions. Among the selected compounds, $7 /$ was found to exhibit considerable activity against entire panel of organisms. $7 /$ showed considerable activity against $S$. aureus, $B$. subtilis and $B$. cereus. It showed moderate activity against $P$. aeruginosa, $E$. coli and $P$. vulgaris. Additionally, the introduction $o$-chloro in the place of $m$-fluoro on the phenyl of 1,3,5-traizine (compound $7 m$ ) renders the molecule significantly more active. The antibacterial activity was increased in the case of $B$. subtilis, while equipotent activity was achieved against $S$. aureus, and $B$. cereus as compared to standard. In the case of $P$. aeruginosa, E. coliand $P$. vulgaris, compound $7 m$ showed moderate activity. The introduction non-halogenated electron withdrawing group showed drastic decline in activity against entire tested microorganisms, compound $7 k$. In the case of compounds having electron donating groups viz.,, $7 n$ and 70 has showed remarkable inhibition of Gram-positive microorganisms.

On the basis of antibacterial results, structure-activity relationship studies suggested that nature of substituent has strong influence on the activity of the compounds, Figure 1. It has been noted that presence of electron withdrawing groups render target analogues more active against Gram positive microorganisms than Gram negative and activity was more confined to the presence of halogen atoms e.g. $7 j, 7 /$ and $7 n$ On the other hand, the antibacterial profile has been significantly improved by the presence of electron donating substituent against Gram negative microorganism viz. 7b, 7c, $7 n$ and $7 o$. This could be explained on the basis of the perturbations brought by these atoms which are very useful to modulate the steric effect on phenyl ring of drug and which in turn alter the ease of penetration of molecule in bacterial cell wall resulting better activity profile. 


\section{$<$ Figure 1>}

\section{$<$ Table 1>}

\section{Antibiofilm activity}

The molecules were also tested for the determination of antibiofilm activity against $S$. aureus and $B$. subtilis. As presented in Table 1, it has been found that, majority of the compounds showed mild to no activity. Among the tested analogues, compound $7 m$ showed more potent activity as compared to cefixime, followed by $7 /$. The rest of the active analogues displayed moderate activity, while no activity in the case of compound $7 a, 7 c, 7 i, 7 k$ and 70 .

\section{Time kill assay}

This assay is widely used for the determination of antimicrobial efficacy of the agent in relation to time against the challenge microorganism. Thus, two most potent molecules ( $7 /$ and $7 m$ ) were further subjected to time kill assay against $S$. aureus and the results have been presented in Figure 2 . It has been found that both compound ( $7 /$ and $7 \mathrm{~m}$ ) showed bacteriostatic action over the duration of time, with most prominent activity in the case of $7 \mathrm{~m}$.

\section{$<$ Figure 2>}

\section{DNA Gyrase Inhibition Assay}

In reference to the excellent antibacterial activity of target analogues, in the next part, we are interested in determination of the mechanism of action of most active analogue $7 /$ and $7 m$ against the DNA gyrase enzyme. The gyrase enzyme is responsible for the introduction of negative supercoils into DNA. It was believed to take part in the initiation and elongation stages during replication and transcription of the bacterial organisms. Thus, its inhibition by a novel class of inhibitor offers distinctive advantage in terms of growing bacterial resistance. The inhibitory profile of compound $7 /$ and $7 \mathrm{~m}$ was determined against the DNA gyrase isolated from $S$. aureus. The results as presents in Figure 3, confirmed that, both the analogues showed significant inhibition of DNA gyrase of $S$. aureus. Particularly, compound $7 \mathrm{~m}$ was proved as an efficient inhibitor of gyrase enzyme than $7 \mathrm{~m}$.

\section{$<$ Figure 3>}

\section{Docking analysis with DNA Gyrase enzyme}


To further exemplify the difference in the mode of interaction with the target receptor, both the compounds were allowed to dock with DNA gyrase protein model using LigandFit module of Discovery Studio 2.5 (Accelrys, Inc., San Diego, CA, USA). On close inspection of the docking interaction as shown in Figure 4, it might be suggested that due to excellent intermolecular H-bonds with Asn54, Asp57, Glu58, Arg144, compound $7 /$ showed excellent interaction with DNA gyrase. Moreover, compound $7 m$ showed prolific interaction with vital key residues, such as, Glu58, Val130, Ile175, lle186 via numerous H-bond with no pi-cation interaction shown in Table 2. Thus, it has been confirmed that, our designed molecules exhibit significant inhibition of DNA gyrase vital for bacterial organisms. It also found in agreement with above inhibition study.

\section{$<$ Table 2>}

\section{$<$ Figure 4>}

\section{In vivo antibacterial activity against $\mathrm{S}$. aureus infection model}

The in vivo antibacterial activity of compound $7 m$ was presented in Figure 5. The results suggested that, compound $7 m$ showed significant inhibition of $S$. aureus infection in test animal. Compound $7 m$ showed dose-dependent reduction of viability of bacteria with maximum activity in $25 \mathrm{mg} / \mathrm{kg}$ treated group. The compound $7 m$ does not found as efficient as ciprofloxacin as standard.

\section{$<$ Figure 5>}

\section{Metabolic Liability of $7 \mathrm{~m}$}

The drugs used clinically are subjected to metabolic process which causes degradation of the molecule in various fragments to increase the polarity for enhanced excretion. The metabolic processes are also frequently associated with the production of metabolite that is toxic in nature. Therefore, in early drug discovery process, the prediction of metabolites of candidate molecule is very vital to prevent iteration in the subsequent procedures and to minimize the possible liabilities and risks coupled with biotransformation. Concerning the excellent antibacterial activity of compound $7 m$, it is worthwhile to define its metabolic liability. In past decade, the computational (in-silico) techniques have significantly contributed for the prediction of metabolites of xenobiotics. These techniques are found more advantageous than the wet experiments and virtually provide prior knowledge about the molecule of interest. In the present study, we have utilized two diverse program, such as, Regioselectivity-Predictor (RS-Predictor) and MetaPrint2D React for the prediction of metabolic liability of compound $7 m$. The FDA 
approved drugs are majorly metabolized by the Cytochrome P450s (CYPs) in site-specific manner to generate metabolites. Therefore, the RS-Predictor was utilized to identify experimentally observed site of metabolism (SOM) within the top two rank positions for substrate sets of each CYP isozyme (1A2, 2A6, $2 \mathrm{~B} 6,2 \mathrm{C} 8,2 \mathrm{C} 9,2 \mathrm{C} 19,2 \mathrm{D} 6,2 \mathrm{E} 1$ and 3A4). The RS-Predictor calibrates an isozyme-specific regioselectivity QSAR (using topological and quantum chemical descriptors) from a set of known isozyme substrates and metabolites by treating each substrate as an individual competition between candidate SOMs. The results of prediction have been given in Figure 6. It has been found that, in majority of CYP isoenzymes, the fluoro containing phenyl group is highly labile SOM, except in the case of CYP2A6 and CYP2D6. On the other hand, many other fragments of the molecule were identified as moderately and fairly labile.

\section{<Figure 6>}

The metabolic process is quite multifaceted that, no single software can able to offer all the information and hence amalgamation of approaches could afford more pragmatic and precise view of biotransformation. Thus, the compound $7 m$ was further analysed with MetaPrint2D-React. It is a metabolic product predictor developed by Unilever Cambridge, Centre for Molecular Science Informatics, University of Cambridge, UK. It utilizes historic metabolic data for SOM, as enumerated by the circular fingerprints which assumes most favourable site to undergo Phase I metabolism. It further finds the similarity between the known SOM and sites that not to be metabolized. The Symyx® Metabolite database was used for the generation of data for the MetaPrint2D, where, for each transformation, the differences between the structure of the reactant and product are identified: groups added or eliminated, bonds broken or made and bonds whose order has changed. To make results simpler, only Phase I reaction (defined as the addition of a single oxygen atom; covering hydroxylation, oxidation and epoxidation) and eliminations (e.g., dealkylation, ester and amide hydrolysis) are taken in account. For an addition, the neighbouring atom next to the added oxygen is marked as a reaction centre. In the case of elimination, a bond gets broken, and both atoms connected by the bond are considered to be reaction centres. Thus, the results of the study as shown in Figure 7, suggested that phenyl of 1,3,5-triazine are considered as a major SOM for the compound $7 m$ in humans. On output, each atom in a $7 m$ was colour coded by its normalized occurrence ratio (NOR) computed and provided in Table 3. A high NOR indicate a more frequently reported site of metabolism in the metabolite database. The normalised occurrence ratio does not indicate how likely a molecule is to be metabolised, but rather the relative likelihood of metabolism occurring at a particular site in the molecule, assuming it is metabolised.

\section{<Figure 7>}

\section{<Table 3>}

\section{Antifungal Activity}


As depicted in Table 4, target compounds exhibits mild to moderate activity against the tested fungal microorganism's viz., Candida albicans, Candida glabrata, Cryptococcus neoformans and Aspergillus niger. It has been observed that, none of the compounds exhibit significant activity against $A$. niger and $C$. neoformans except compound $7 d$. Entire set of compounds displayed significant inhibition of Candida Spp where the pattern of inhibition is much more prominent against $C$. albicans than $C$. glabrata. Compound $7 d$ displayed significant activity against the entire tested organism and more specifically, it found equipotent to standard drug against $C$. neoformans. On close inspection of Table 4 , it has been observed that there is no specific correlation exists between substituent and the inhibitory activity. However, to improve this activity profile and get insight about structure-activity relationships, further studies are currently underway in our laboratory and reported subsequently.

\section{Conclusion}

The molecules were proved as effective antibacterial agent via inhibition of DNA gyrase as a mechanism together with significant antifungal activity. The molecules hold significant promise for the development of novel antibacterial agent.

\section{References}

1. Rogers GB, Carroll MP, Bruce KD (2012) Enhancing the utility of existing antibiotics by targeting bacterial behaviour?. Br J Pharmacol. 165(4):845-57. 2. Zakeri B, Lu TK (2012) Synthetic biology of antimicrobial discovery. ACS Synth Biol. 2(7):358-72. 3. Roux D, Pier GB, Skurnik D (2012) Magic bullets for the 21st century: the reemergence of immunotherapy for multi- and pan-resistant microbes. $J$ Antimicrob Chemother.67(12):2785-7. 4. Fair RJ, Tor Y (2014) Antibiotics and bacterial resistance in the 21 st century. Perspect Medicin Chem. 6:25-64. 5. The antibiotic resistance crisis: part 1: causes and threats. P T (2015) 40(4):277-83. 6. After 2015: infectious diseases in a new era of health and development (2014) Philos Trans R Soc Lond B Biol Sci. 369(1645):20130426. 7. Roberts RR, Hota B, Ahmad I, et al (2009) Hospital and societal costs of antimicrobial-resistant infections in a Chicago teaching hospital: implications for antibiotic stewardship. Clin Infect Dis. 49(8):1175-84 8.

http://www.who.int/news-room/fact-sheets/detail/antibiotic-resistance 9. Nweneka CV, Tapha-Sosseh N, Sosa A (2009) Curbing the menace of antimicrobial resistance in developing countries. Harm Reduct J. 6:31. 10. Wright GD (2016) Antibiotic Adjuvants: Rescuing Antibiotics from Resistance. Trends Microbiol. 24(11): 862-871. 11. Ahmed A, Azim A, Gurjar M, Baronia AK (2014) Current concepts in combination antibiotic therapy for critically ill patients. Indian J Crit Care Med. 18(5):310-4. 12. Bollenbach T (2015) Antimicrobial interactions: mechanisms and implications for drug discovery and resistance evolution. Current Opinion in Microbiology. 27: 1-9. 13. Woodford N, Ellington MJ (2007) The emergence of antibiotic resistance by mutation. Clinical Microbiology and Infection. 13(1): 5-18. 14. Bhat HR, Singh UP, Thakur A, Ghosh SK, Gogoi K, Prakash A, et al (2015) Synthesis, antimalarial activity and molecular docking of hybrid 4-aminoquinoline-1,3,5-triazinederivatives. Exp Parasitol. 157:59-67. 15. Srivastava JK, Dubey P, Singh S, Bhat HR, Kumawat MK, Singh UP (2015) Discovery of novel 1,3,5-triazine-thiazolidine- 
2,4-diones as dipeptidyl peptidase-4 inhibitors with antibacterial activity targeting the $S 1$ pocket for the treatment of type 2 diabetes. RSC Adv. 5: 14095-14102 16. Srivastava JK, Awatade NT, Bhat HR, Kmit A, Mendes K, Ramos M, et al (2015) Pharmacological evaluation of hybrid thiazolidin-4-one-1,3,5-triazines for NF-KB, biofilm and CFTR activity. RSC Adv. 5: 88710-88718 17. Singh B, Bhat HR, Kumawat MK, Singh UP (2014) Structure-guided discovery of 1,3,5-triazine-pyrazole conjugates as antibacterial and antibiofilm agent against pathogens causing human diseases with favorable metabolic fate. Bioorganic and Medicinal Chemistry Letters. 24:3321-5. 18. Dubey V, Pathak M, Bhat HR, Singh UP (2012) Design, Facile Synthesis, and Antibacterial Activity of Hybrid 1,3,4-thiadiazole-1,3,5-triazine Derivatives Tethered via -S- Bridge. Chemical Biology and Drug Design. 80:598-604. 19. Srivastava JK, Pillai GG, Bhat HR, Verma A, Singh UP (2017) Design and discovery of novel monastrol-1,3,5-triazines as potent anti-breast cancer agent via attenuating Epidermal Growth Factor Receptor tyrosine kinase. Sci Rep. 7(1): 5851. 20. National Committee for Clinical Laboratory Standards (1982) Standard Methods for Dilution Antimicrobial Susceptibility Test for Bacteria Which Grow Aerobically, Villanova, NCCLS, p. 242. 21. Tsuji BT, Yang JC, Forrest A, Kelchlin PA, Smith PF (2008) In vitro pharmacodynamics of novel rifamycin ABI0043 against Staphylococcus aureus. Journal of Antimicrobial Chemotherapy. 62(1):156-160. 22. Osburne MS, Maiese WM, Greenstein M (1993) An assay for the detection of bacterial DNA gyrase inhibitors. J Antibiot (Tokyo). 46(11):1764-6. 23. Blanche F, Cameron B, Bernard FX, Maton L, Manse B, Ferrero L,et al. (1996) Differential behaviors of Staphylococcus aureus and Escherichia coli type II DNA topoisomerases. Antimicrob Agents Chemother. 40: 2714-20. 24. Singh K, Kumar S, Shekhar S, Dhawan B, Dey S (2014) Synthesis and biological evaluation of novel peptide BF2 as an antibacterial agent against clinical isolates of vancomycin-resistant enterococci. J Med Chem. 57(21):8880-5. 25. Zaretzki J, Bergeron C, Rydberg P, Huang TW, Bennett KP, Breneman CM (2011) RS-predictor: a new tool for predicting sites of cytochrome P450-mediated metabolism applied to CYP 3A4. J Chem Inf Model. 51(7):1667-89. 26. National Committee for Clinical Laboratory Standards (2002) Reference method for broth dilution antifungal susceptibility testing of yeasts. Approved standard M27-A2. National Committee for Clinical Laboratory Standards, Wayne, PA. - 2. National Committee for Clinical Laboratory Standards, Clinical and Laboratory Standards Institute (CLSI): Reference method for broth dilution antifungal susceptibility testing of filamentous fungi, as the document is M38-A., Wayne, PA. USA. NCCLS, 2002.

\section{Tables}

Table 1: Antibacterial activity of compounds 7 (a-o). 


\begin{tabular}{|c|c|c|c|c|c|c|c|c|}
\hline \multirow[t]{2}{*}{ Compound } & \multicolumn{6}{|c|}{ Minimum Inhibitory Concentration $\left(\mu \mathrm{g} \mathrm{mL}^{-1}\right)$} & \multicolumn{2}{|c|}{$\begin{array}{c}\text { Antibiofilm activity } \\
\left(\mu \mathrm{g} \mathrm{mL} \mathrm{m}^{-1}\right)\end{array}$} \\
\hline & $\begin{array}{l}S . \\
\text { aureus }\end{array}$ & $\begin{array}{l}B . \\
\text { subtilis }\end{array}$ & $\begin{array}{l}B . \\
\text { cereus }\end{array}$ & $\begin{array}{l}P . \\
\text { aeruginosa }\end{array}$ & $\begin{array}{l}\text { E. } \\
\text { Coli }\end{array}$ & $\begin{array}{l}P . \\
\text { vulgaris }\end{array}$ & S. aureus & B. subtilis \\
\hline $7 a$ & ND & ND & 50 & 100 & ND & 100 & ND & ND \\
\hline $7 \mathrm{~b}$ & 50 & 12.5 & 12.5 & 50 & 50 & 12.5 & $>50$ & $>50$ \\
\hline $7 \mathrm{c}$ & ND & 25 & 50 & 12.5 & 6.25 & 12.5 & ND & ND \\
\hline $7 d$ & 25 & 50 & 100 & 12.5 & 12.5 & 6.25 & $>50$ & $>50$ \\
\hline $7 e$ & 12.5 & 100 & 12.5 & 6.25 & 12.5 & 12.5 & 50 & $>50$ \\
\hline $7 \mathrm{f}$ & ND & 100 & 50 & 25 & 25 & 6.25 & $>50$ & $>50$ \\
\hline $7 g$ & 100 & 50 & 100 & 25 & 25 & 25 & $>50$ & $>50$ \\
\hline $7 \mathrm{~h}$ & 12.5 & 12.5 & 12.5 & 50 & ND & ND & 50 & 50 \\
\hline $7 \mathrm{i}$ & 50 & 50 & 25 & 100 & ND & 100 & ND & ND \\
\hline $7 \mathrm{j}$ & 6.125 & 12.5 & 12.5 & ND & 100 & 50 & 50 & 50 \\
\hline $7 \mathrm{k}$ & 50 & ND & 50 & ND & 50 & ND & ND & ND \\
\hline 71 & 6.25 & 12.5 & 12.5 & 25 & 25 & 50 & 25 & 50 \\
\hline $7 \mathrm{~m}$ & 3.125 & 6.25 & 3.125 & 12.25 & 25 & 12.5 & 12.5 & 25 \\
\hline $7 \mathrm{n}$ & 25 & 25 & 50 & 12.5 & 12.5 & 25 & 50 & 50 \\
\hline 7o & 100 & 25 & 12.5 & 6.25 & 12.5 & 12.5 & ND & ND \\
\hline $\begin{array}{l}\text { Cefixime } \\
\text { (Standard) }\end{array}$ & 3.125 & 3.125 & 3.125 & 3.125 & 6.25 & 3.125 & 25 & 25 \\
\hline
\end{tabular}

Table 2: DNA gyrase inhibitory activity of compounds $\mathbf{7 l}$ and $\mathbf{7 m}$ along with molecular interactions.

\begin{tabular}{|l|c|c|}
\hline \multirow{2}{*}{ Compound } & H-bond & Pi-cation \\
\cline { 2 - 3 } & & \\
\hline 71 & Asn54, Asp57, Glu58, Arg144 & Arg84 \\
\hline $7 \mathrm{~m}$ & Glu58, Val130, Ile175, Ile186 & No \\
\hline
\end{tabular}

Table 3: The normalized occurrence ratio (NOR) of compound $7 \mathrm{~m}$ as determined by MetaPrint2D React.

\begin{tabular}{|l|l|}
\hline Red & $0.66<=$ NOR $<=1.00$ \\
\hline Orange & $0.33<=$ NOR $<0.66$ \\
\hline Green & $0.15<=$ NOR $<0.33$ \\
\hline White & $0.00<=$ NOR $<0.15$ \\
\hline Grey & Little $/$ no data \\
\hline
\end{tabular}

Table 4: Antifungal activity of compounds 7 (a-o). 


\begin{tabular}{cccccc}
\hline Compound & \multicolumn{5}{c}{ Minimum Inhibitory Concentration $\left(\mu \mathrm{mL}^{-1}\right)$} \\
\cline { 2 - 5 } & C. albicans & C. glabrata & C. & neoformans & A. niger \\
\hline $7 \mathrm{a}$ & - & - & - & - \\
$7 \mathrm{~b}$ & 10 & 10 & - & 20 \\
$7 \mathrm{c}$ & - & 10 & 50 & 20 \\
$7 \mathrm{~d}$ & 1.25 & 1.25 & 1.25 & 5 \\
$7 \mathrm{e}$ & 5 & 10 & 5 & - \\
$7 \mathrm{f}$ & 10 & - & - & 20 \\
$7 \mathrm{~g}$ & - & 5 & - & - \\
$7 \mathrm{~h}$ & 20 & 20 & - & - \\
$7 \mathrm{i}$ & 10 & - & 10 & - \\
$7 \mathrm{j}$ & 5 & 10 & - & - \\
$7 \mathrm{k}$ & 20 & 10 & 20 & - \\
$7 \mathrm{l}$ & 20 & 10 & - & - \\
$7 \mathrm{~m}$ & 10 & 20 & - & - \\
$7 \mathrm{n}$ & 5 & - & - & - \\
$7 \mathrm{o}$ & 2.5 & - & 1.25 & & - \\
Amphotericin B & 0.16 & 0.32 & & & \\
(Standard) & \multicolumn{5}{c}{} \\
\hline
\end{tabular}

\section{Figures}

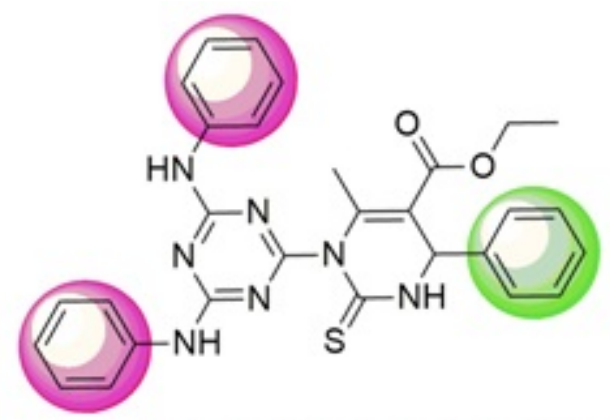

\section{Gram -ve organisms}

$R$ and $R$ " = Electron donating group

Order of activity

$\mathrm{OH}>\mathrm{OCH}_{3}$

\section{Gram + ve organisms}

$R$ and $R$ " = Electron withdrawing group Order of activity $\mathrm{Cl}>\mathrm{F}>\mathrm{Br}>\mathrm{NO}_{2}$

\section{Figure 1}

Structure-activity relationship study of 7 (a-o) as antibacterial. 

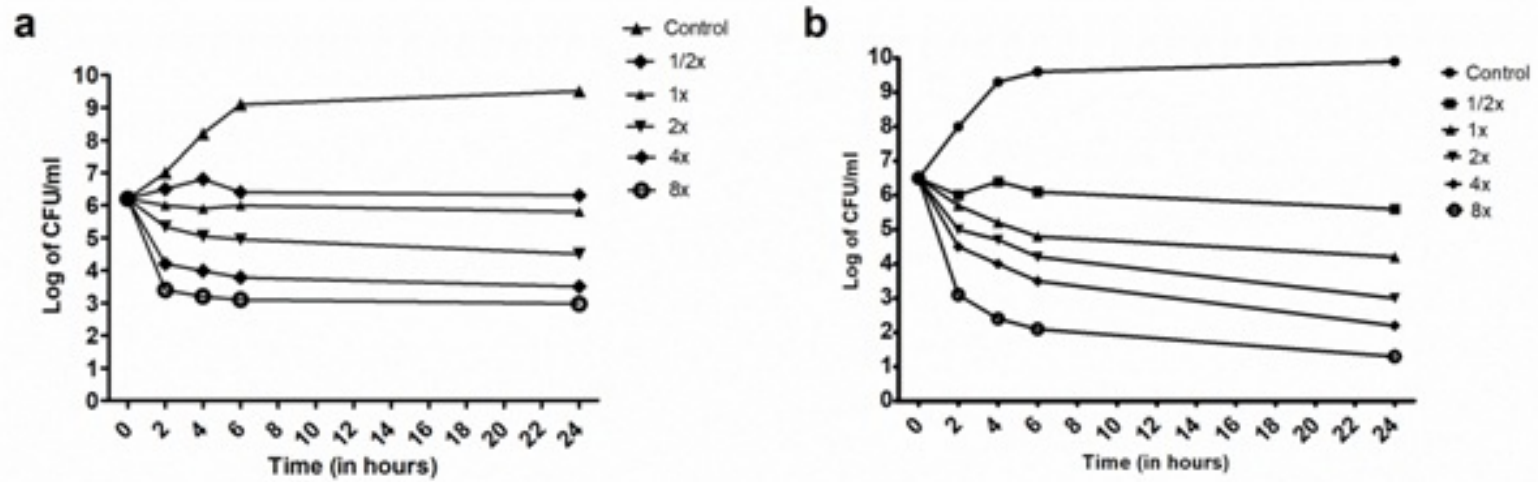

Figure 2

Time kill assay of compound 7l (a) and 7m (b).

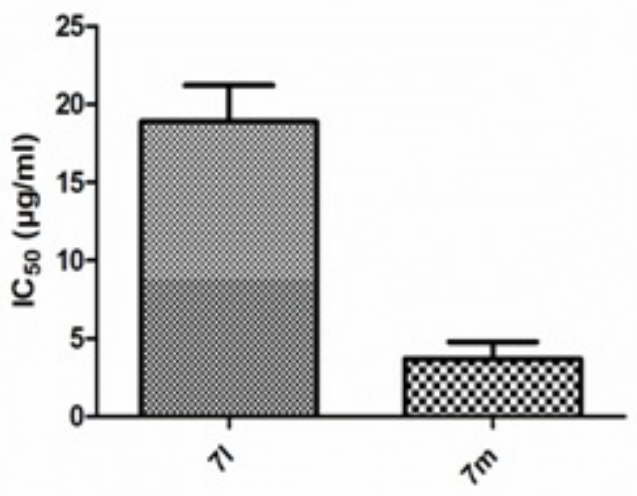

Figure 3

S. aureus DNA Gyrase inhibitory activity of compound $7 \mathrm{I}$ and $7 \mathrm{~m}$. 

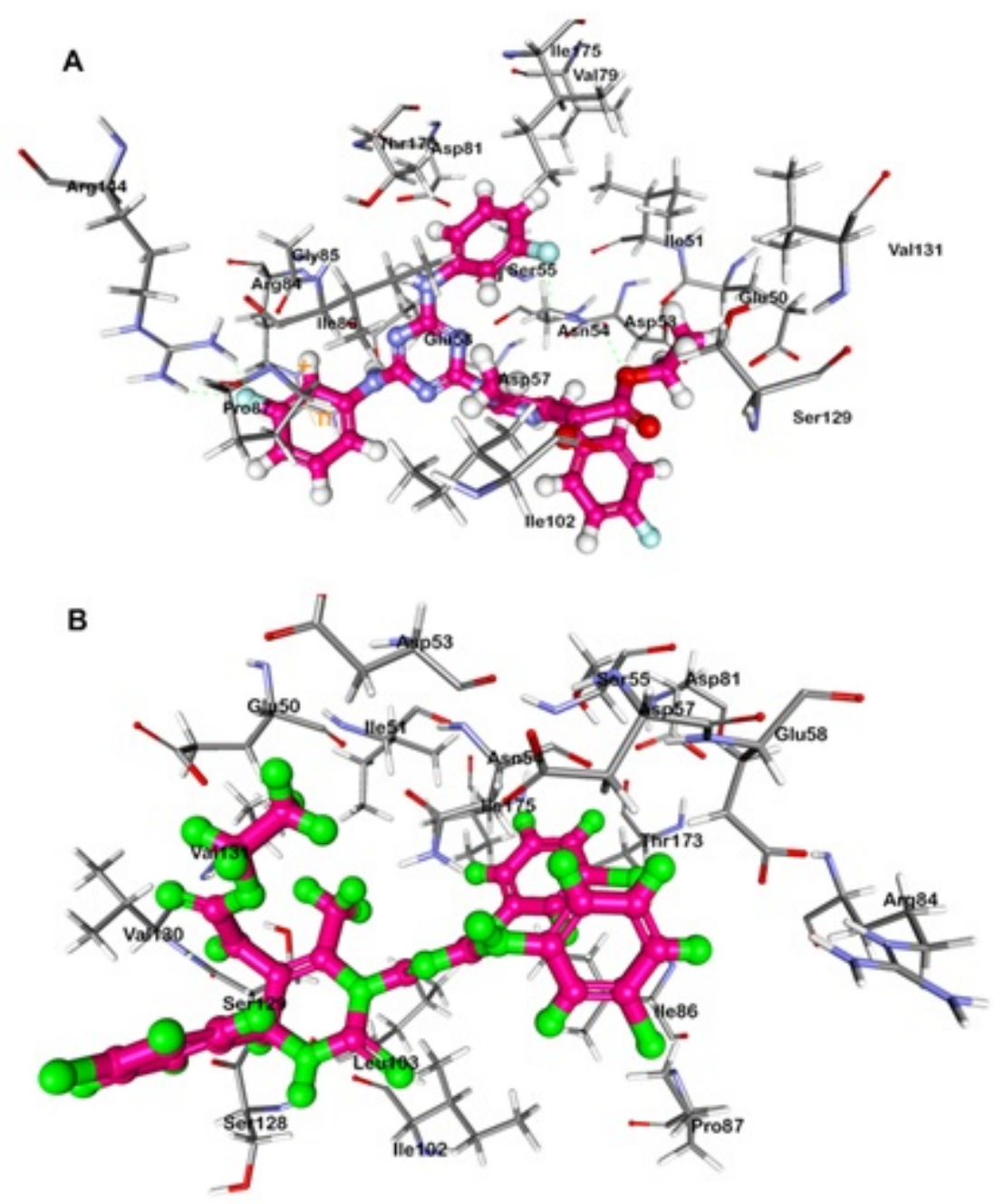

Figure 4

Docked orientation of compound (A) $7 \mathrm{I}$ and (B) $7 \mathrm{~m}$ in the active site of bacterial DNA gyrase enzyme.

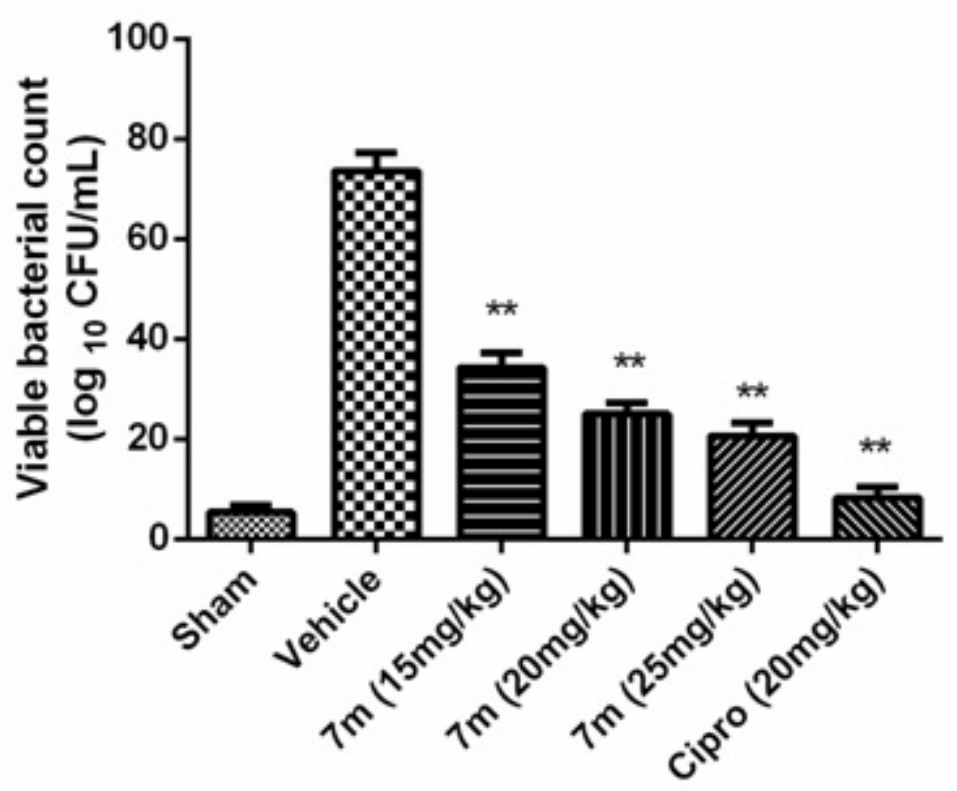


Figure 5

Antibacterial activity of compound $7 \mathrm{~m}$ against $\mathrm{S}$. aureus murine model. Results presented as mean $\pm \mathrm{SD}$. ** $p>0.01$ compared with vehicle.

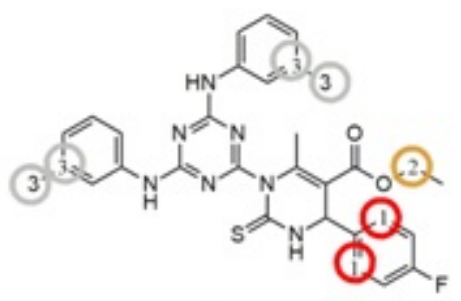

a

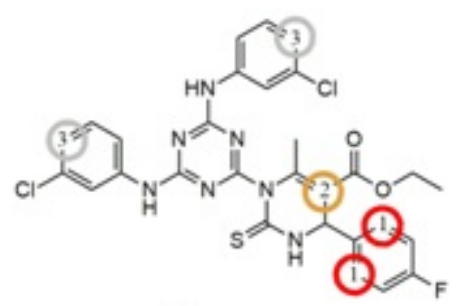

d

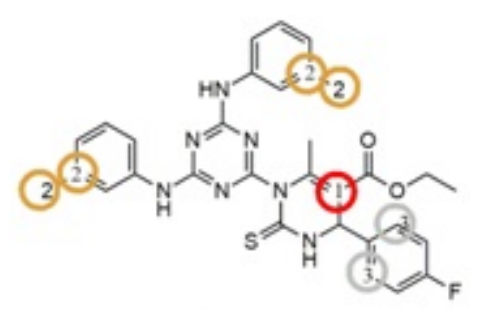

g

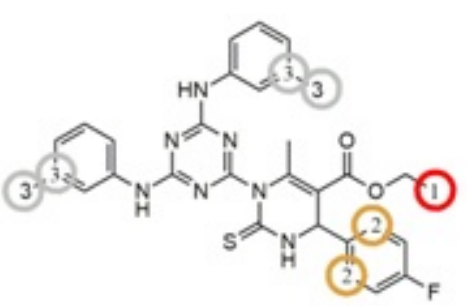

b

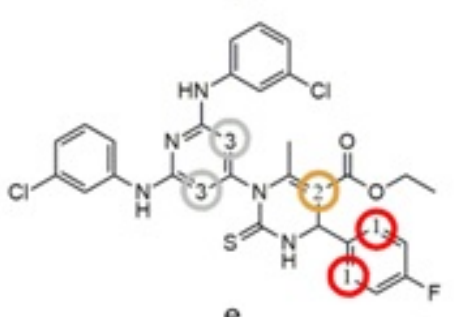

e

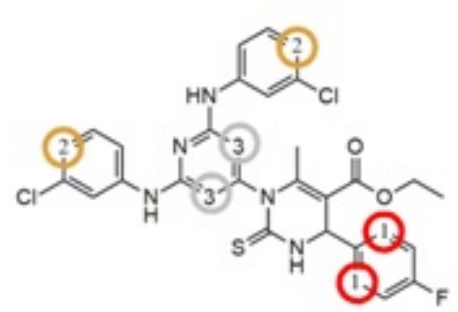

$\mathrm{h}$

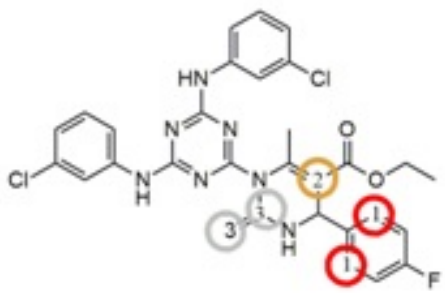

c
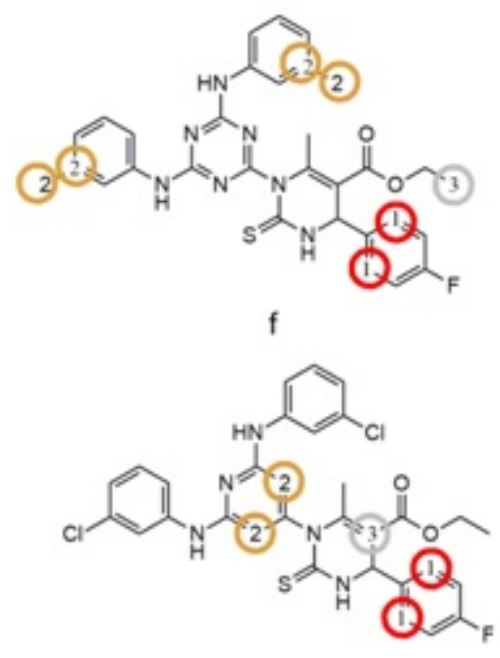

i

\section{Figure 6}

Prediction of SOM by RS-Predictor of compound 7m, where a) CYP1A2, b) CYP2A6, c) CYP2B6, d) CYP2C8, e) CYP2C9, f) CYP2C19, g) CYP2D6 h) CYP2E1 i) CYP3A4. Colour code: RED: highly labile, orange: moderately labile and grey: fairly labile. 


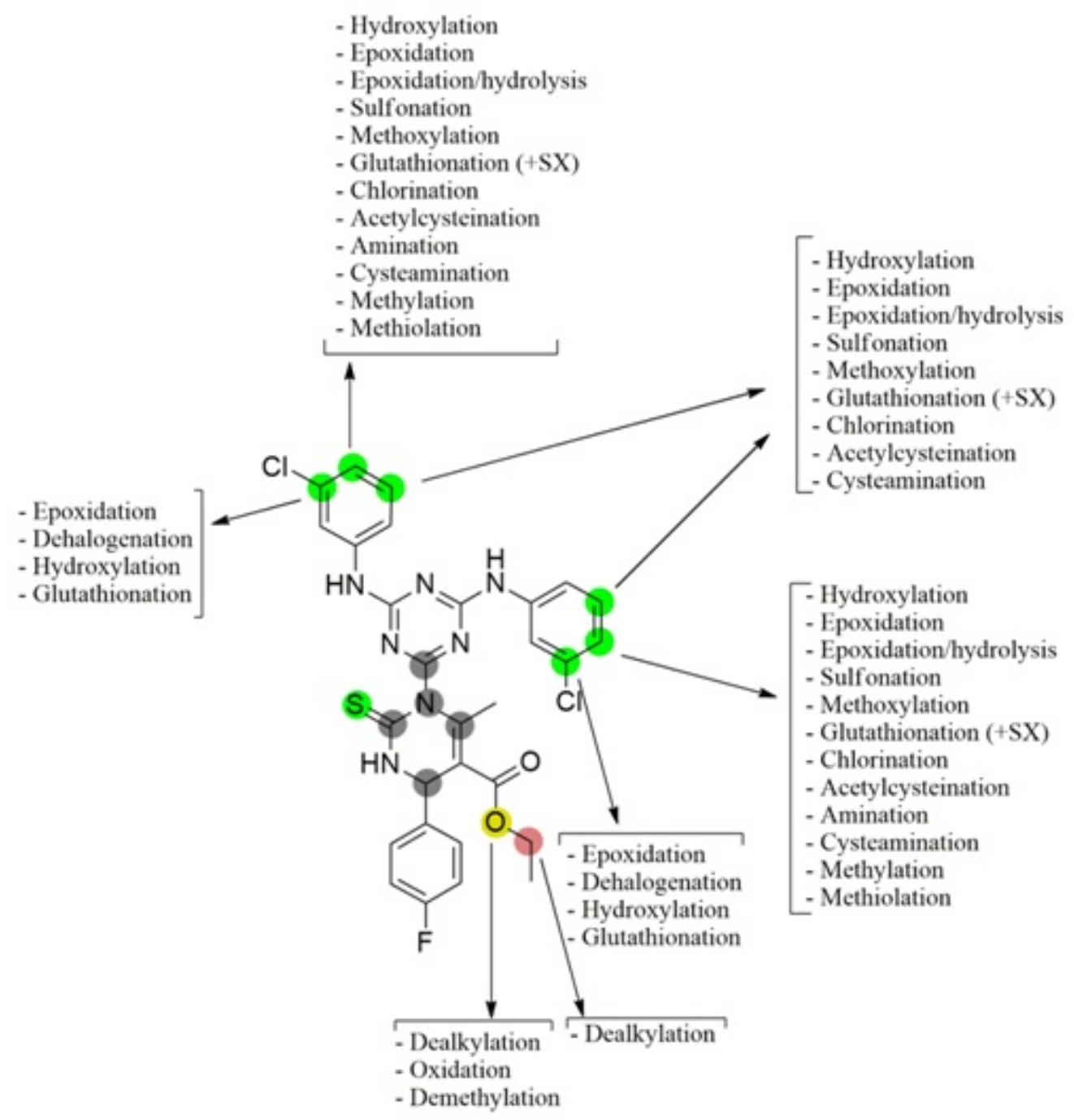

Figure 7

Prediction of site of metabolism (SOM) in human for compound 7m using MetaPrint2D React.

\section{Supplementary Files}

This is a list of supplementary files associated with this preprint. Click to download.

- GraphicalAbstract.docx 